\title{
Financial Analysis Simulation of Marketing Commodities
}

\author{
Avijit Jain ${ }^{1}$, Amit Pathak ${ }^{2}$, N Farheen Safoora ${ }^{3}$, Neantha Louiza Vaz ${ }^{4}$, M Prajakta ${ }^{5}$ \\ Department of Information Science and Engineering, The National Institute of Engineering, Mysore, Karnataka, India ${ }^{1,2,3,4,5}$
}

\begin{abstract}
This document presents the aim and implementation details that are necessary to get the desired output and arrive at an appropriate conclusion. According to the geometric Brownian motion model the future price of financial stocks has a lognormal probability distribution and their future value therefore can be estimated with a certain level of confidence. The goal of this paper is to study the modelling future stock prices. The assumptions on which this model is based meet the financial market laws and rules imposed by the Market Efficiency Hypothesis. These rules and laws suppose that only present information about a stock efficient to determine the future price of this that stock. Data mining is a process that is used to search for patterns or relationship between various elements of a given set of data. Data mining also refers to the derivation of relevant information from a given data set.
\end{abstract}

Keywords: Stochastic Modelling, Agricultural economics, Random walk, futures market, data analysis, Data Mining.

\section{INTRODUCTION}

According to the geometric Brownian motion model, the returns on a certain stock in successive, equal periods of time are independents and normally distributed. So theoretically the geometric Brownian motion seems to be a good way to model future stock.

In practice however it shows some shortcomings, especially when it is used to model the price over short periods of time.

The prices of agricultural commodities keep fluctuating. The prices can go up by $10 \%$ or sometimes go down by $20 \%$. Hence we need something that can help us speculate the future market.

Whereas it is more accurate when used for modelling stock prices over longer periods of time. This is due to the fact that the expected rate of return and volatility of a stock are assumed to be constant. To assess the accuracy of the model, it is preferable to model these parameters as stochastic function of time and not as constants.

\section{DEFINING MAKETING COMMODITIES}

\section{A. CARDAMOM}

"Queen of Spices"-Cardamom is one of the most exotic spices. Kerala, Karnataka and Tamil Nadu are the cardamom growing states in India. In 2013-14, India's production was estimated to be around 17000 MT. [1].

There has been a fall in the export of cardamom due to heavy competition, yet the cardamom industry is still thriving due to the increase in domestic consumption. The growth of the Pan industry, the single largest consumer of Cardamom, has been one of the major factor for increase in domestic consumption. Cardamom prices are affected by domestic and international supply-demand parameters. The major importing countries are the Arabian nations and the demand peaks during the Ramadan fasting period. The crop is highly susceptible to pests, diseases and the vagaries of the monsoon. This also has a strong influence on the prices [2].
Cardamom is traded at the MCX (Multi-Commodity Exchange of India Pvt Ltd).

\section{MARKETING TREND}

In 2012 the prices reached an all-time high of $1500 \mathrm{Rs} / \mathrm{Kg}$ in the month of August and within a span of two months they plummeted to as low as $840 \mathrm{Rs} / \mathrm{Kg}$ in November 2012[3].

Unexpected rain in the initial stages of South West monsoon raised prices to a great extent. The crop failure in Guatemala (due to lack of pest control) during this period also resulted in a shortage of supply. Hence, exports from India increased a lot. Exports rose from approximately 1,200 tonnes in 2010-11 season to above 4,000 tonnes in 7 months of 2011-12 season [4].

But later on, higher arrivals in major spot markets, carryover stock, sluggish domestic and overseas demand and conducive weather conditions in major growing areas led to the downfall of the prices [4]. The ban on the pan masala and gutka manufacturing sector also worsened the situation by decreasing the demand.

The following graph presents the price trends over a period of two years.

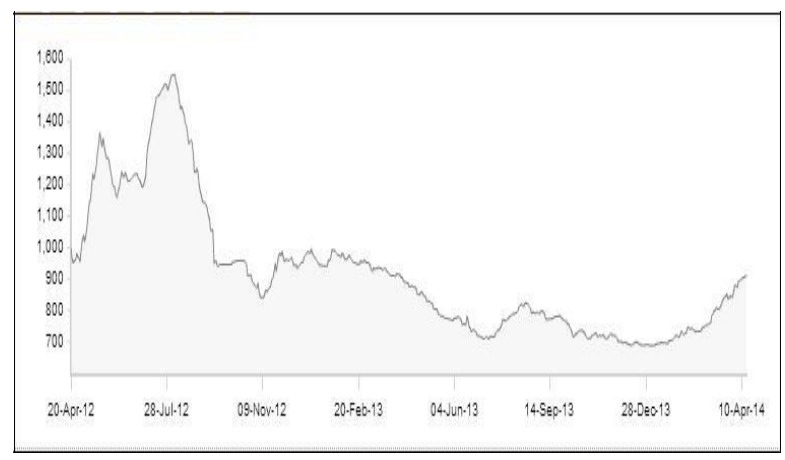

The above graph Fig 3.1 shows the future prices of cardamom for the financial year (2012-2013 and 2013-2014) [5]. 


\section{B. CHANA}

Chana or Chickpea is a major pulse crop in the Indian subcontinent and several other countries. Known for rich protein content, Chana is used as an edible seed as well as making flour. Chana is broadly divided into two categories Kabuli and Desi-- according to the colour, seed size and taste.

India is the leading producer and consumer of Chana in the world. The Indian production is estimated to be between 4-7 million tons per year. Normally Chana accounts for around 40 percent of India's total pulses crop production of 12-15 million tons. Major producing states are Madhya Pradesh, Uttar Pradesh, Rajasthan and Maharashtra.

A fragmented market with a very long value chain is the main characteristics of the present Chana market scenario in the country. Commission agents, brokers, wholesalers, flourmills and retail outlets are the key players in the market.

The sentiments of traders play a significant role currently, as a consequence of the lack of free-flow of information. There is also high substitutability between pulses in India among the consumers. So the price of other major pulses like tur, yellow peas, green peas etc also influence the prices of Chana.

Besides output and demand, other key parameters shaping Chana prices include carryover stocks, imports and the extent of substitution with other pulses [6].

\section{MARKETING TREND}

Chana prices have fallen from Rs5000 made in October 2012 to Rs2500 in August 2013.

Output in this season estimated at 8.88 million tonnes. It failed to follow price seasonality in 2013 and remained bearish throughout the year.

MSP for rabi 2014 season fixed at Rs3100 per quintal up by Rs100 from last year. Currently prices are hovering around Rs3000 across major mandis.

Market is urging imposition of import duty on pulses or allowing exports as prices have fallen sharply in this year [7].

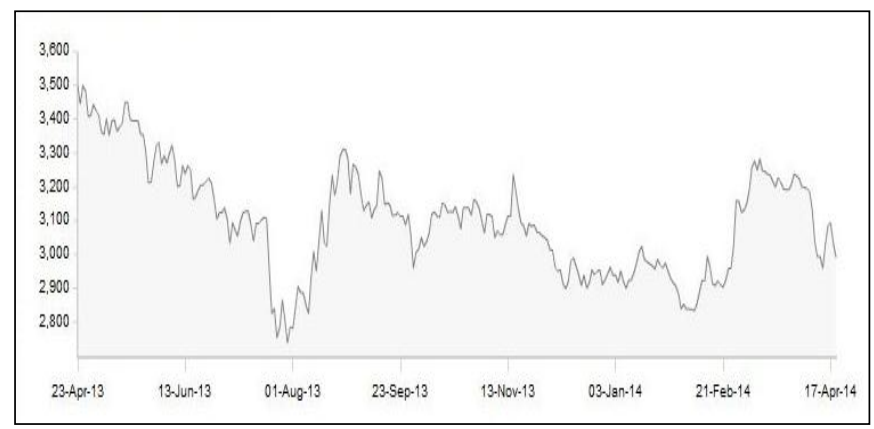

The above graph Fig 3.2 shows the future prices of Chana for the current financial year (2013-2014) [8].

\section{SOYBEAN}

Soybean is one of the major oilseed crops in the world. It comes in three forms: - soya seed, soya oil and soya meal. It constitutes $24 \%$ share of the vegetable oils in the international market. United States, China, Argentina, and Brazil are among the major exporters

India is the 6th largest producer in the world yet, doesn't meet its production, hence it is the largest importer too.

The soya bean crop is being produced in India since the past 30 years.

In 1960's-1970's the domestic production met the country's demand. In 1980's the production and consumption grew at rapid pace increasing the imports.

The soya bean prices are influenced by a number of factors including weather conditions of the field area, Supply-Demand scenario in consuming countries ( large population and adequate production), International prices( the price movements in domestic and global agencies) etc. The prices in India are also affected by the government policies and import tariffs [9].

\section{MARKETING TREND}

In the first half prices are decided by the quality of the crop while weather is the key factor in the second half.

Indian soybean prices rose significantly in 2013 due to the falling rupee and high demand from Iran and China [10].

The weather conditions remain key factor in determining soybean price trend both domestic and international markets in the month of July 2013.

Incessant rains in July 2013, in the major soy growing belt of MP and Maharashtra, led to damage of the soy crop. However, the area under the crop remains significantly higher and marginal yield losses did not have a significant impact on the output.

Prices may fluctuate further in 2014, with the possibility of lower prices due to increase in global supply (major exporters like Argentina and Brazil).

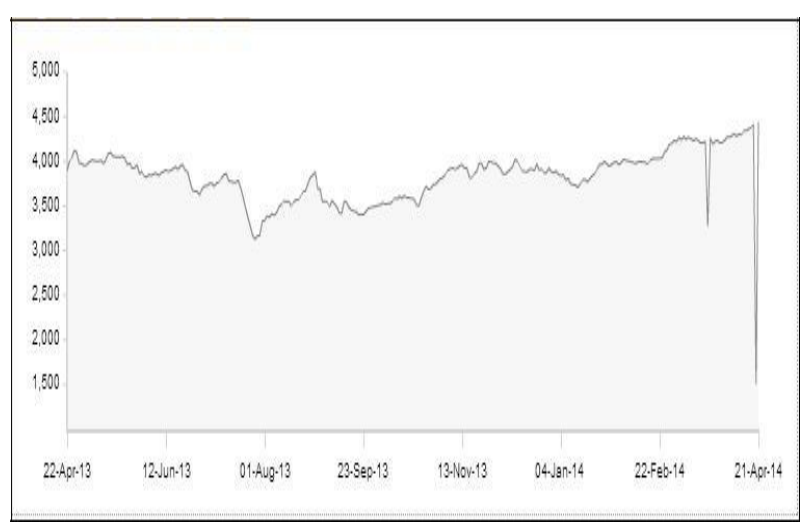

The above graph Fig 3.3 shows the Soybean future prices of the current financial year (2013-2014) [9]. 


\section{THE MODEL}

\section{A. EFFICIENT MARKET HYPOTHESIS (EMH)}

The EMH was a rule that governed the financial world but it has been defied to some extent by various academicians. According to the hypothesis, the stock prices of any commodity follow a random walk. The prices always fully reflect the information available and no profit can be made from information based trading. The more efficient is the market, lesser is the predictability of price changes.

\section{B. RANDOM WALK THEORY}

The random walk theory is the occurrence of an event determined by a series of random movements - in other words, events that cannot be predicted.

This theory when applied to stock prices states that the prices follow a random walk which makes it impossible to predict the prices. The Random walk theory is consistent with the EMH [12].

\section{TECHNICAL ANALYSIS}

Technical Analysis is a method of evaluating securities by analyzing statistics generated by market activity, such as past prices and volume. Technical analysts do not attempt to measure a security's intrinsic value, but instead use charts and other tools to identify patterns that can suggest future activity.

Technical analysts believe that the historical performance of stocks and markets are indications of future performance. They sharply contrast the Efficient Market Hypothesis and the random walk theory.

Academics cannot conclusively prove or agree on whether the stock market truly operates via a random walk or based on predictable trends because there are published studies that support both sides of the issue.

Here, we make an attempt to consolidate both the theories and create a model that can predict future stock prices with a realistic probability.

\section{GEOMETRIC BROWNIAN PATH MODEL}

A geometric Brownian motion (GBM) is a continuoustime stochastic process in which the logarithm of the randomly varying quantity follows a Brownian motion (also called a Wiener process) with drift [13].

Mathematically, in simple terms, the model can be expressed by the following equation:

$$
X_{t}=\mu+X_{t-1}+\epsilon_{t}
$$

Where

$X_{t}$ is the log of the price of the asset at time

$\mu$ is a drift constant $t$

$\epsilon_{t}$ is a random disturbance term

Interpreting it in the stochastic differential form we get,

$\mathrm{d} X_{t}=\mu X_{t} \mathrm{~d} t+\sigma X_{t} \mathrm{~d} B_{t}$

Where B denotes the Brownian motion, $\mu$ is the drift coefficient and $\sigma$ is volatility. The stochastic process $\mathrm{Xt}$ is called stock value.

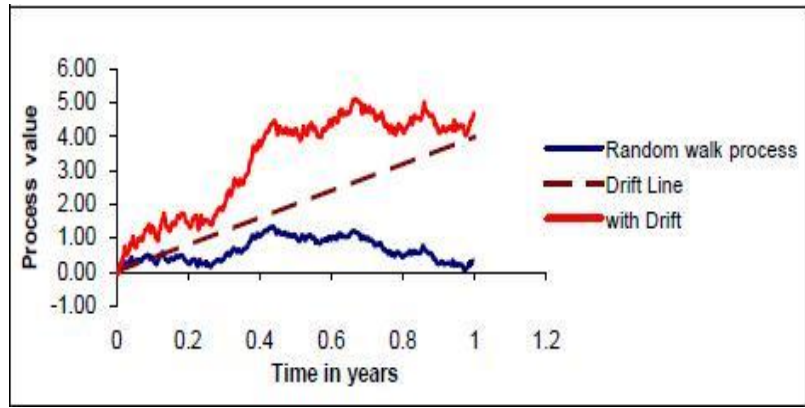

Fig. 4.1 Graphical representation [16]

This is the geometric Brownian motion model for the future stock prices.

\section{E. PARAMETER REQUIRED}

Drift $(\mu)$ : It is a constant which tells us the amount of shift of the average value of a stochastic process. It can be positive or negative.

Volatility $(\sigma)$ : It is the constant characteristic of the stock prices that tells us the measure of the fluctuations of the stock prices. Relatively high volatility means that the stock price varies continuously within relatively large interval [16]

\section{F. IMPORTANT ASSUMPTIONS}

(A) The expected returns of GBM are independent of the value of the process (commodity/stock price), which agrees with what we would expect in reality [14].

(B) A GBM process only assumes positive values, just like real commodity prices.

(C) The price returns are normally distributed [15].

Assumptions (A) and (B) are straightforward and hold true in our case. To validate the assumption (C), we took the daily change in prices of the three chosen commodities and the following histogram resulted. 


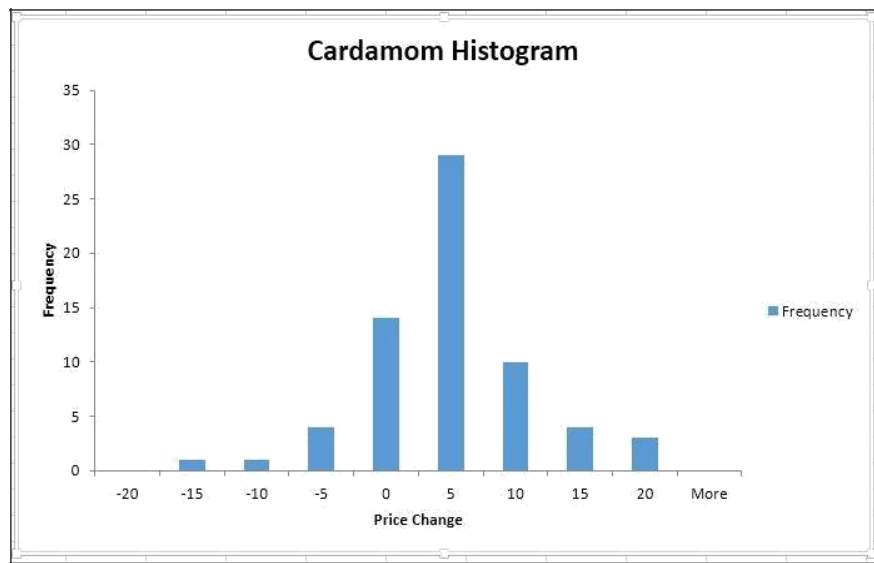

Fig. 4.2: Histogram for Cardamom

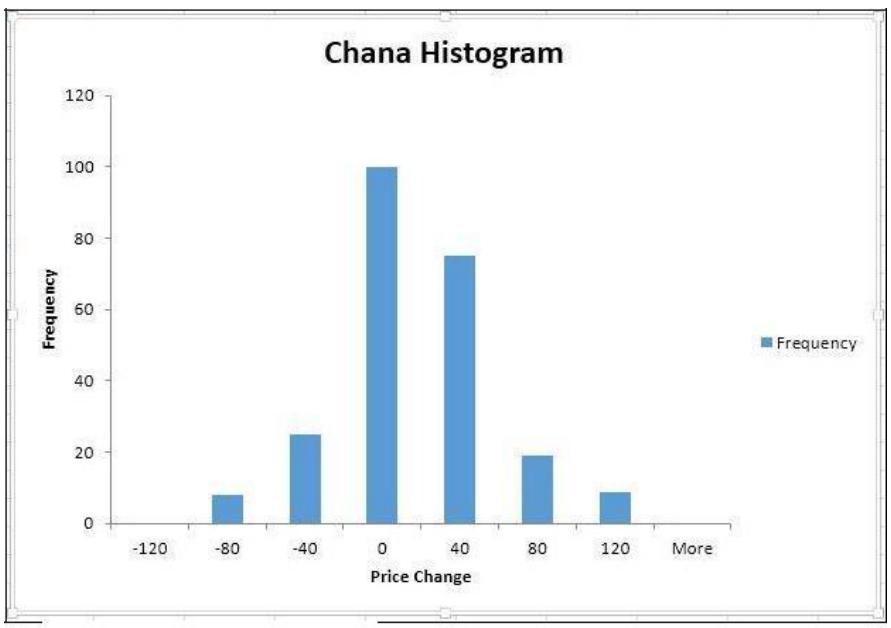

Fig. 4.3: Histogram for Chana

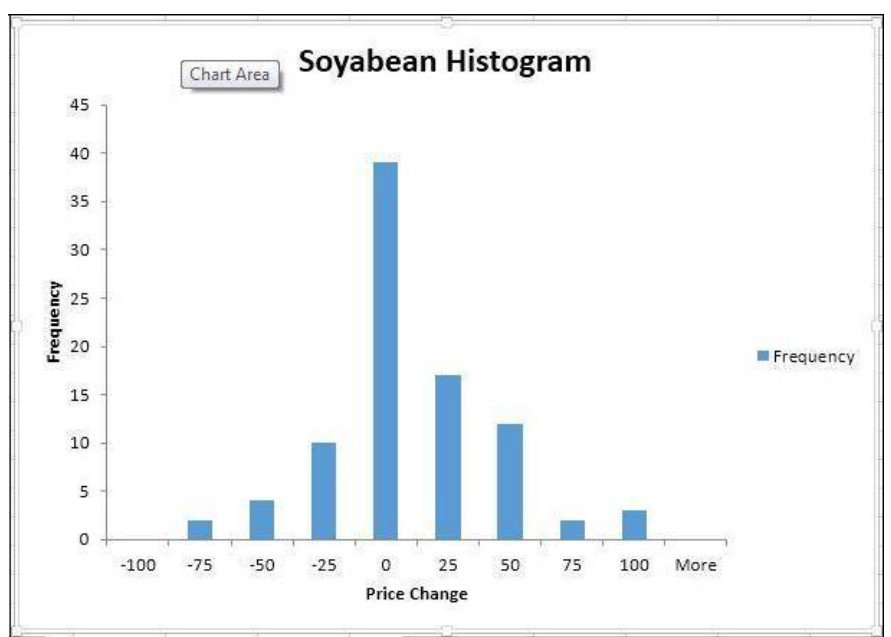

Fig. 4.4: Histogram for Soybean

All the three histograms are looking normal, with chana and soyabean centred around 0 , while cardamom centred around 5

This validates our assumption (C) about the Geometric Brownian Path Model.

\section{WORKFLOW OF THE MODEL}

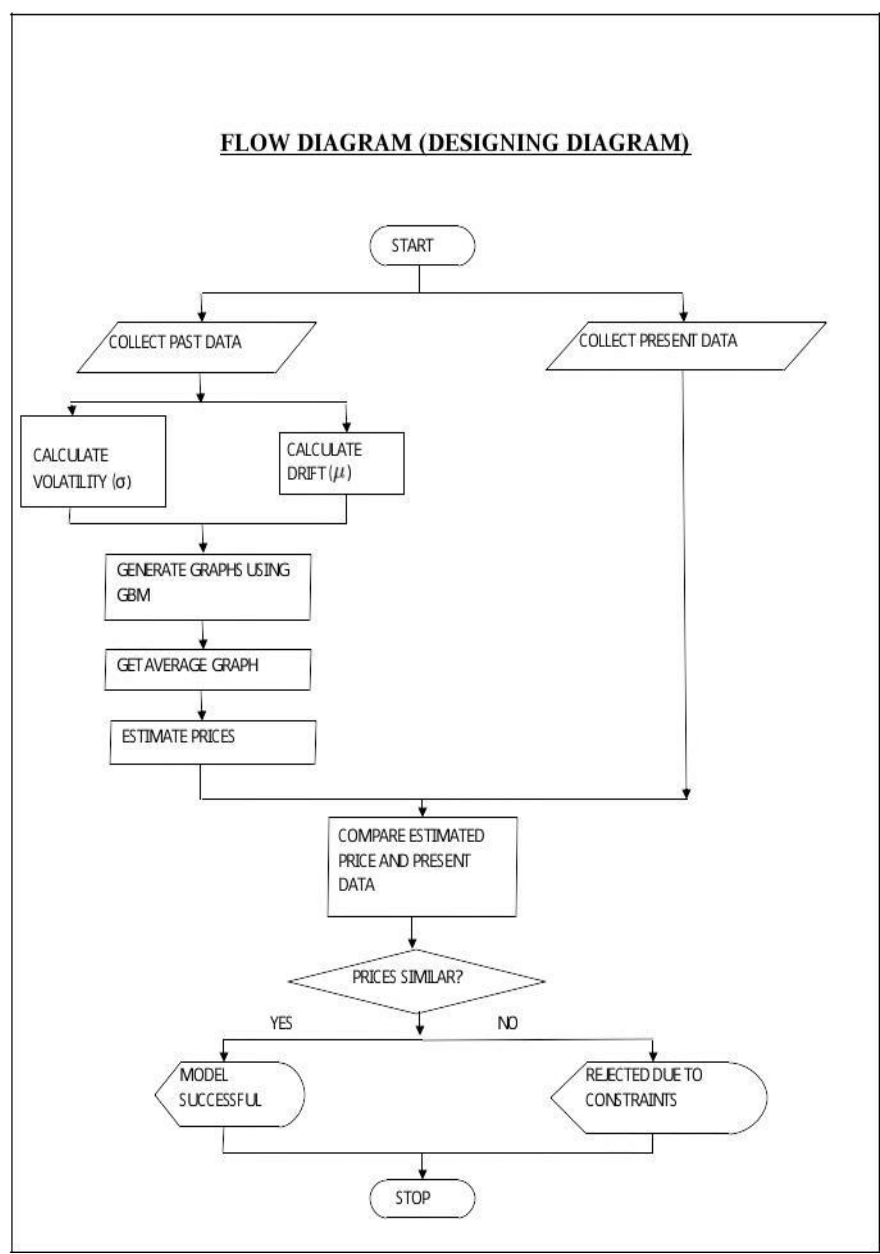

Fig 5.1 Flowchart of the process

\section{TESTING THE MODEL}

Up to now, the geometric Brownian motion that has been closely studied and the distribution of the future stock price have been given. The properties and hypothesis of the geometric Brownian motion have also been successfully tested.

The major question that remains unanswered is: does the theoretical model, with assumptions as stated before, reproduce a correct image of the reality of stock price. To answer this question I will use the model to generate a series of simulated stock values and compare the results to the real data. Using the formulas of the expected value and the confidence interval, the value of the stock at a future time will be estimated and also compared to the real stock value at the same future time.

\section{RESULTS}


The stock prices of each of the three commodities of the year 2013 were used to derive the drift and volatility of the commodity. The following were the observed values:

\begin{tabular}{|l|l|c|}
\hline Commodity & Drift & Volatility \\
\hline Cardamom & -0.354 & 0.127 \\
\hline Chana & -0.124719 & 0.220535 \\
\hline Soybean & 0.233505 & -0.315491 \\
\hline
\end{tabular}

Table 1: Drift and Volatility values of Commodities

These two parameters were then used to create the Geometric Brownian path of the commodity prices for three different scenarios -for the next 10 days, for the next month and for the next 3 months. Each of the figures presented below contains 1000 Brownian paths (in blue), an average of all the 1000 paths (in red) and the original price curve of the commodity (in yellow).

\section{Chana:}

1. January 2014

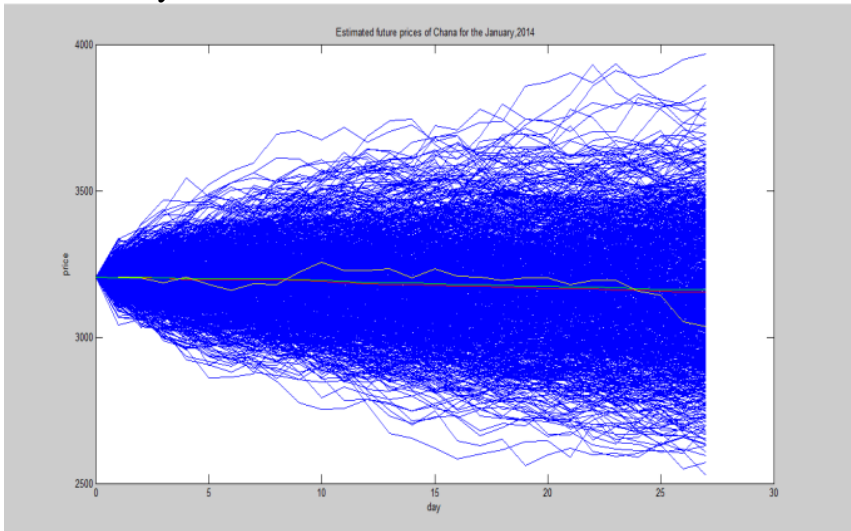

Fig. 8: Brownian Path for Chana - Jan 2014

2. January 2014 - April 2014

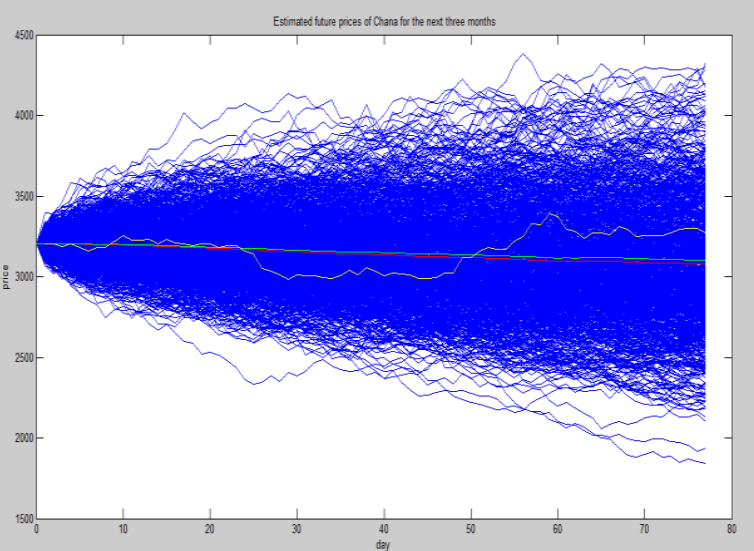

Fig. 9: Brownian Path for Chana - Jan-Apr 2014

Soybean:
1. January 2014

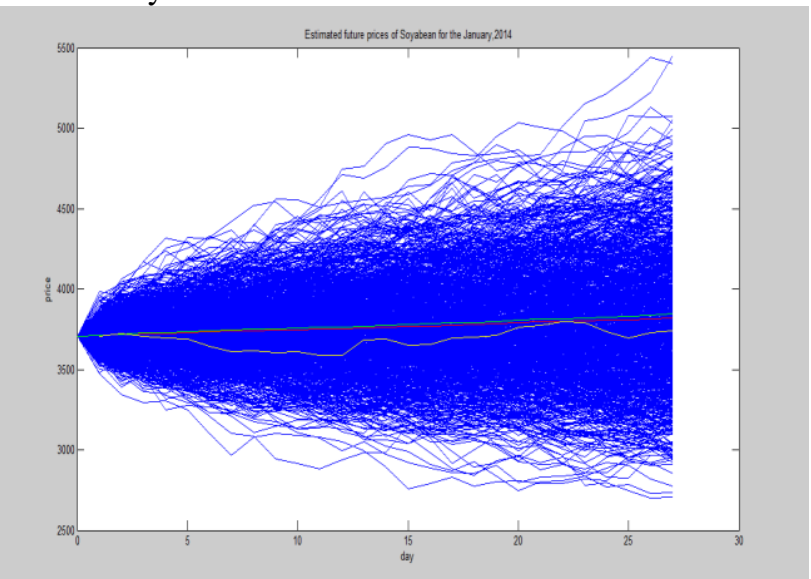

Fig. 10: Brownian Path for Soybean - Jan 2014

2. January 2014 - April 2014

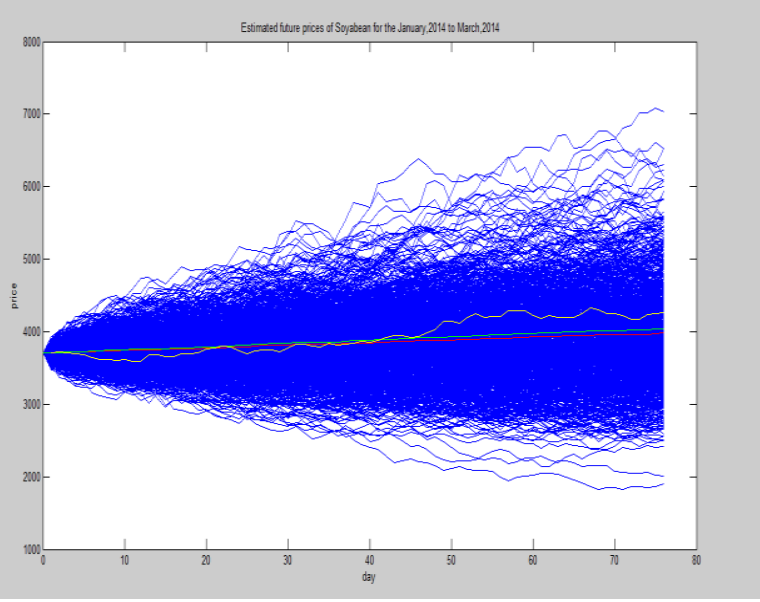

Fig. 11: Brownian Path for Soybean - Jan-Apr 2014

Cardamom:

3. January 2014

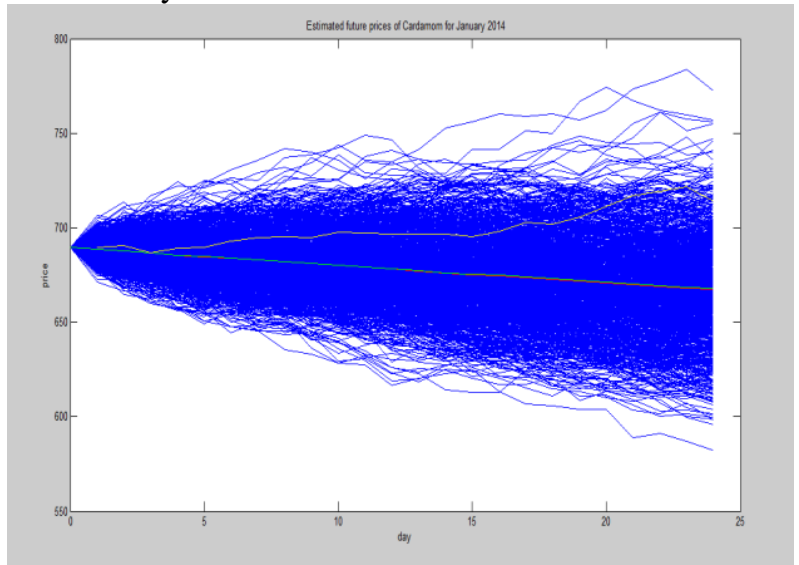

Fig. 12: Brownian Path for Cardamom - Jan 2014

4. January 2014 - April 2014 


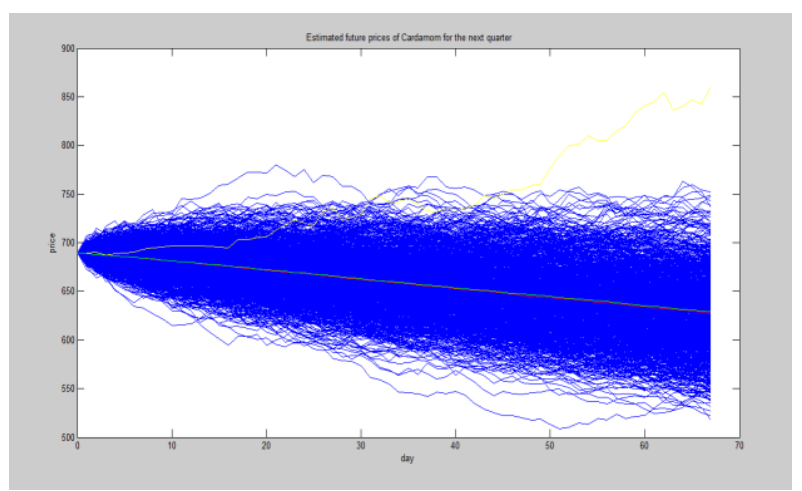

Fig. 13: Brownian Path for Cardamom - Jan-Apr 2014

\section{OBSERVATIONS AND INTERPRETATIONS}

The following observations were made from the graphical results of the model:

1. For the commodities Chana and Soybean, the original curve was, in most cases, very close to the average of the Brownian paths. The model was a perfect fit for these two commodities and able to predict the future prices with high probability.

2. For Cardamom, the original curve was close to the average of the Brownian paths only for the subsequent month i.e. January 2014. For the period after January 2014, the curve deviated significantly from the average. Thus for Cardamom, the model is unable to predict the future prices with a reasonable certainty.

The confidence interval for three future values of the prices was calculated. The results are mentioned below:

\begin{tabular}{|c|c|c|c|c|}
\hline \multirow[t]{2}{*}{ Date } & \multirow[t]{2}{*}{$\begin{array}{c}\text { Expected } \\
\text { Value }\end{array}$} & \multicolumn{2}{|c|}{$\begin{array}{l}\text { 95\% Confidence } \\
\text { Interval }\end{array}$} & \multirow[t]{2}{*}{$\begin{array}{c}\text { Real } \\
\text { Value }\end{array}$} \\
\hline & & Up & Low & \\
\hline \multicolumn{5}{|c|}{ Commodity: Soyabean } \\
\hline 1-1-14 & 3723 & 3909 & 3537 & 3722 \\
\hline 1-2-14 & 3790 & 3979 & 3600 & 3733 \\
\hline $1-4-14$ & 3986 & 4185 & 3786 & 4170 \\
\hline \multicolumn{5}{|c|}{ Commodity: Chana } \\
\hline 1-1-14 & 3202 & 3362 & 3042 & 3202 \\
\hline $1-2-14$ & 3153 & 3310 & 2995 & 3012 \\
\hline 1-4-14 & 3079 & 3233 & 2925 & 3180 \\
\hline \multicolumn{5}{|c|}{ Commodity: Cardamom } \\
\hline 1-1-14 & 689 & 724 & 655 & 689 \\
\hline 1-2-14 & 668 & 701 & 634 & 720 \\
\hline $1-4-14$ & 628 & 660 & 597 & 860 \\
\hline
\end{tabular}

Table 2: Confidence Interval Measure of the Prediction of Prices

It can be easily observed from the table that Chana and Soybean prices can be predicted within the $95 \%$ confidence interval. The same is not true for Cardamom.

\section{CONCLUSION}

As it has been observed, our model depicts an accurate picture of chana and soyabean future prices. The actual values align perfectly with the estimated value for smaller intervals up to a month. The real value after 4 months also lies in the confidence interval predicted by the model.

However, the model fails to replicate this behaviour for cardamom. One of the major reason for this limitation is that the trading volumes of Cardamom at MCX, which is around 1500 MT per month is far below the trading volumes of Chana and Soyabean at NCDEX which is around 30000 MT per month. The model's accuracy depends upon the traded volumes of the commodities.

\section{A. ADVANTAGES}

As stated in the introduction, modelling of stock prices is about modelling new information about stocks. In this dissertation modelling has been realized through the quantification of a stochastic part in the general expression of the model.

The results of the simulation performed in this work do not always match those of the theoretical model even if the assumptions on which the model is based meet the financial market rules.

The geometric Brownian motion shows less accuracy in short time modelling. This is due to the assumption that the parameters drift and volatility are constant. However its accuracy may be improved by modelling the parameters as stochastic function of time and other macroeconomic factors, which may influence the course the stock price.

\section{B. LIMITATIONS}

Fails to estimate the prices of commodities that are produced in small quantities.

More the fluctuation in prices the lesser accurate it is. One of the limitations of the model is the constant nature of drift and volatility with respect to time. The drift and volatility are calculated based on the yearly prices of the commodities. They are not dependent on the timely fluctuations in the futures market. For example, during the period of Ramadan, cardamom loses much of its volatile behavior because of continuous high demand from the Arabian nations. Our model does not depict this change in the market.

\section{FUTURE SCOPE}

A time-varying drift and volatility, which would explain patterns of the market, are prospects for future research for this model.

\section{REFERENCES}

1] "Products-Spices-Cardamom - MCX." Products, Web. 20Jan.2014. $<$ http://www.mcxindia.com/sitepages/contractspecification.aspx?Pr o ductcode $=$ CARDAMOM $>$.

[2] "Cardamom,MCX Cardamom Futures, Cardamom Prices." Web. 2 Feb. 2014 <http://www.commodityonline.com/commodities/spices/cardamom. 
p hp>.

[3] Krishnan, C.P. "Cardamom Prices under Pressure." The Hindu Business Line. Web. 1 Feb. 2014.

[4] "Cardamom Prices Rise." Web. 2 Feb. 2014. <http://www.businessstandard.com/article/markets/cardamom-prices-may-rise-over-rs-2000-per-kg-112050600061_1.html>.

[5] "Today's Cardamom Price." Cardamom Spot Price \& Historical Charts on MCX-SPOT Exchange | Motilal Oswal. Web. 2 Feb. 2014 <http://www.motilaloswal.com/Broking/Markets/Commodity/MCXSpot/CARDAMOM.htm>.

[6] "Chana, NCDEX Chana Futures, Chana Prices." Web. 17 Apr. 2014 <http://www.commodityonline.com/commodities/spices/chana.php>.

[7] "Chana Market Outlook -2013-14" Web. <http://www.inditrade.com/UploadResearch/635195113606848750_ Chana\%20Market\%20Outlook\%20-2013-14.pdf

[8] "Today's Chana Price." Chana Futures Price \& Historical Charts on NCDEX Exchange | Motilal Oswal. Web. 20 May. 2014. <http://www.motilaloswal.com/Broking/Markets/Commodity/NCDE X/CHARJDDEL.htm>.

[9]"2014 Corn, Soybean Price Prospects." Corn and Soybean Digest. Web. 7 Feb. 2014. <http://cornandsoybeandigest.com/marketing/2014corn-soybean-price-prospects>.

[10] Rathod, Tushar. "Reaping High Returns." Agri Commodities. Web. 6 Feb. 2014.

[11] Gupta, Vivek. "Farming Profit." Farm Commodities. CapitalVia Global Research. Web. 6 Feb. 2014

[12] Burton G. Malkiel - The Efficient Market Hypothesis and Its Critics, Princeton University -CEPS Working Paper No. 91 April 2003

[13] Diego Maldonado, Random walks, discrete Brownian motion, and numerical stochastic integration -Kansas State University, Manhattan.

[14] Hull, John (2009). "12.3". Options, Futures, and other Derivatives (7 ed.).

[15] Harper, David. "Monte Carlo Simulation With GBM" Web. 26 Feb, 2009. <http://www.investopedia.com/articles/07/montecarlo.asp> Abdelmoula Dmouj, Stock price modelling: Theory and Practice, MSc Thesis, Vrije Universiteit, Faculty of sciences Amsterdam, The Netherlands. 